\title{
RAÍZES DO TERROR
}

Maged Elgebaly ${ }^{1}$

O atentado contra Charlie Hebdo foi um ato terrorista que condenamos de modo contundente. Esse terrorismo, como todo fenômeno complexo, tem múltiplas causas e, por isso, precisa ser tratado a partir de várias perspectivas (econômica, histórica, cultural, política e educativa).

Economicamente, o Oriente Médio vive uma contrarrevolução que envolve conflitos entre tradições locais do capitalismo clientelista ${ }^{2}$ e estilos novos de vida das elites neoliberais eurocêntricas. Ambas correntes querem dominar as energias, os comércios, os capitais e os sistemas de viver. Essa contrarrevolução envolve também a crise ambiental e a grande recessão, causada pela falta de distribuição das riquezas e pela carência de um sistema político baseado na organização dos trabalhadores. Deste modo, o atual sistema não garante a sustentabilidade dos recursos, porque não almeja a libertação das relações exploratórias na aprendizagem e no trabalho.

Politicamente, o terrorismo contemporâneo teve suas raízes profundas no sistema neoliberal que se formou nos anos de 1970 com as políticas de abertura econômica (Infitaah) do Anwar Al Sadat. Os governos neoliberais utilizavam os radicais islamistas para barrar a esquerda, a exemplo dos islamistas do Al Qaeda, que foram treinados pela CIA para combater a ex-URSS. A partir dos anos de 1990, auge do projeto neoliberal, os islamistas se multiplicaram em células e associações. Era visível a infiltração do wahabismo $^{3}$ na formação de elites políticas e militares, em virtude da necessidade de energia do Golfo, berço desse movimento fundamentalista.

\footnotetext{
${ }^{1}$ Coordenador do Departamento de Língua Portuguesa da Universidade de Aswan (Aswan - Egito).

${ }^{2} \mathrm{O}$ capitalismo clientelista é um termo usado por Raymond Vernon que descreve uma economia em que o sucesso nos negócios depende das estreitas relações entre os empresários e funcionários do governo. Isto pode ser demonstrado pelo favoritismo na distribuição de autorizações legais, nos subsídios do governo, nos incentivos fiscais especiais, ou outras formas de dirigismo.

${ }^{3} \mathrm{O}$ wahabismo é um movimento salafista, é dizer parte de uma interpretação literal do Alcorão e um estilo de vida igual ao de Maomé. 0 movimento foi fundador por Muhammad ibn 'Abd al-Wahhab.(1703 - 1792), que era fortemente influenciado pelo teólogo do século XIII Taqi al-Din ibn Taymiyya, que pregou durante
} 
Esse fundamentalismo engendrou um estancamento cultural que propiciou a proliferação dessas interpretações fundamentalistas nas práticas islâmicas. Nesse momento, os islamistas começaram a praticar atos terroristas contra intelectuais que se opunham ao processo de islamização política das sociedades árabes, e muitas partes dos países árabes começaram a ficar a margem dos processos de desenvolvimento, sofrendo agudas exclusões em termos de educação, de saúde e de trabalho. A situação piorou ainda mais nas áreas periféricas e teve seu auge com a crise financeira de 2008. As medidas militares do sistema neoliberal criaram um ambiente intolerante que fomenta as interpretações totalitárias do Islã, porque as lógicas mercantil e militar vão ao encontro das lógicas sectária, tribal e terrorista. Toda essa situação alimentou o conflito com as forças seculares civis que lutam pelos direitos humanos e pelo respeito da diversidade.

A nova colonização penetra o sistema político em todos os setores dos governos da região através de uma rede complexa de monopólios capitalistas industriais promovidos pelo Banco Mundial. Essa instituição global controla, por meio dos seus empréstimos, os programas de educação que procuram adaptar o ser humano local aos modelos de consumo desses monopólios e intimidar qualquer tentativa crítica.

Então, há uma correlação progressiva entre o extremismo, a tirania da economia do mercado livre, a centralidade da acumulação de capital e a ascensão de um sistema imperialista de transnacionais que suprimem os controles democráticos reais, e com essa situação se aumentam as taxas dos lucros, da violência simbólica e do terrorismo. Ruy Braga 4 explica: "O atentado contra Charlie Hebdo foi uma explosão brutal de violência nutrida por décadas de reprodução dissimulada de um tipo de violência sistemática cujas razões últimas devem ser buscadas no recente ciclo da mundialização capitalista”. Por isso, observa-se uma relação entre as forças imperialistas e suas atividades econômicas e culturais neocoloniais e o extremismo religioso, que produz os grupos terroristas e as formas de guerra psicológica contra a esquerda democrática árabe para intimidar sua movimentação interna e externa rumo a um Estado Secular, Plural e Democrático.

A ação democrática no Oriente Médio envolve críticas aos estados árabes que insistem na preservação do termo "Estado Islâmico" nas suas constituições, na manutenção de partidos islâmicos religiosos e na afirmação de uma governabilidade 
totalitária com base na censura exercida pelas instituições de caráter islâmico. Nessa crítica, temos que problematizar os discursos estatais árabes quando pregam uma compreensão moderada do Islã, uma versão que só pode ser alcançada num sistema secular e democrático que encoraje o cidadão a participação livre na renovação do sistema axiológico caducado pelo enfraquecimento da industrialização.

A propaganda de um suposto estado islâmico "moderado", "moderno" e "liberal" de caráter religioso e supostamente "democrático" termina promovendo interpretações religiosas que permitem o confisco das liberdades de pensamento, crença e expressão. Ou seja, esse modelo de governo "islâmico democrático" aprofundou o sectarismo religioso com sua ação subjetiva violadora dos direitos humanos, uma situação ideal para que as potências imperialistas possam saquear os recursos da periferia.

As milícias dos estados do Oriente Médio praticam o sequestro, a tortura, o assassinato, a espionagem das comunicações, a falsificação de acusações arbitrárias contra inocentes e o abuso do mecanismo de prisão preventiva com o pretexto da guerra contra o terrorismo. Tais atrocidades formam o imaginário do inconsciente dos futuros takfiristas, que classificam os que descumprem a lei islâmica (sharia) como infiéis (kafir) e os declaram excomungados (takfir), passíveis de serem executados.

Perante essa situação, as organizações de direitos humanos continuam resistindo e tentando defender o espaço público, e procuram inspecionar prisões para garantir a equidade do sistema e a conscientização dos direitos dos presos. Ademais, as forças democráticas árabes apresentaram vários projetos para a reforma das instituições de segurança pública para garantir sua integridade. Há vozes que reivindicam um inquérito transparente sobre o suposto papel da cultura de repressão dos aparelhos de segurança na proliferação dos projetos do terrorismo. Por isso, Slavoj Zizek ${ }^{5}$ considera o fundamentalismo uma reação mistificadora contra uma falha real do neoliberalismo que lentamente minará a si próprio, a única coisa que pode salvar o valor da vida (que, para nós, deve estar acima de qualquer outro) é uma esquerda renovada. Para nós, à diferença das posturas que defendem que o fundamentalismo seja reação à modernização, acreditamos que seja uma reação à falta de modernização humana e justa. Isso forma uma série de problemas na solução das causas culturais do terrorismo, pois as periferias ficaram sem instituições educativas modernas e as existentes nos centros continuam

\footnotetext{
5 ZIZEK, Slavoj.“Pensar o atentado contra Charlie Hebdo”. Blog da Boitempo, 2015. http://blogdaboitempo.com.br/2015/01/12/zizek-pensar-o-atentado-ao-charlie-hebdo
} 
cultivando mentes eurocêntricas, unidimensionais e monossêmicas que não aceitam as diversidades, as diferenças e as críticas.

É necessário, para enfrentar o extremismo religioso, recuperar o caráter plural na interpretação crítica dos clássicos da cultura árabe. Também é necessário não esquecermos que o terrorismo não se limita a atacar a Charlie Hebdo, a lista de ativistas democratas e intelectuais em países árabes que os terroristas atacaram nas últimas décadas é grande. Na atual cojuntura, relembramos o assassinato de Farag Foda e as absurdas sentenças persecutórias contra Nasr Hamid Abu Zayd. Ambos intelectuais participaram da inovação da hermenêutica histórica moderna do discurso islâmico ao fazerem uma análise crítica da produção dos sentidos do Corão, e assim, atribuíram um caráter metafórico e histórico na interpretação dos textos e fizeram ênfase no legado histórico cultural comum entre as varias crenças que coexistem na região de Oriente Médio.

No nível das relações de gênero, o clima sectário, resultado do fundamentalismo, fomenta a separação entre homens e mulheres na esfera pública e promove clichês sociais hostis à mulher e sua participação social e econômica. Por isso, encontramos cada vez mais feministas árabes como Nawal Saadawi e Fatema Mernissi que criticam ativamente a violação sistemática dos direitos das mulheres nos discursos e nas práticas patriarcais dessas religiosidades extremistas.

No meio dessa situação, Slavoj Zizek6, nos instiga a analisar o projeto políticoideológico que emerge como reação contra qualquer injustiça. Hoje, há um projeto expansionista de um Califado Islâmico Totalitário na África e nos Países Árabes. Esse projeto, resultado do debilitado estado social e da sua destruição na mão dos governos neoliberais, provoca discórdia e violência sistemática. Esse cenário evoca três fatos marcantes na memória cultural popular da região: as Cruzadas (1096 - 1291), o acordo de Sykes-Picot em 1916, que dividiu os países árabes, e a Naqba (catástrofe, em árabe) em 1948 com a expulsão dos palestinos do seu território.

Essas memórias deram bases para o surgimento de grupos funcionais, como os chamados os islamistas e seus agentes liberais, que fazem as guerras por procuração dos Estados Unidos contra o nacionalismo árabe quando este desafia os interesses

${ }^{6}$ ZIZEK, Slavoj. "Eu sou estúpido e maldoso”, Blog da Boitempo, 2015. http://blogdaboitempo.com.br/2015/02/16/eu-sou-estupido-e-maldoso-zizek-esclarece-sua-posicaosobre-o-je-suis-charlie 
estratégicos dos sistemas neocoloniais. Alain Badiou ${ }^{7}$ coloca o dedo na ferida da tragédia atual:

De um lado, temos os grupos de assassinos fortemente armados, acenando para garantir o perdão de Deus; e do outro, em nome dos direitos humanos e da democracia, selvagens expedições militares internacionais, que destroem estados inteiros, que fazem milhares de vítimas, e chegam para negociar com os bandidos mais corruptos em busca de poços, minas, recursos alimentares e enclaves onde as grandes empresas possam prosperar.

Trata-se de forças que propagam o medo de qualquer rumo que conduza à independência dos países periféricos a essas políticas neoliberais. Temos visto a manipulação política com a "Guerra contra o Terrorismo", a consequente violação sistemática dos direitos humanos em nome da segurança nacional, e a criminalização dos movimentos sociais - em vez de apoiá-los na realização do sonho de uma coexistência pacífica entre os diferentes pontos de vista, ou na construção de outra ordem mundial baseada na busca real de uma ética e uma estética da justiça das diferenças. Ruy Braga ${ }^{8}$ aponta:

O objetivo do atentado foi atingir certa espetaculização para recrutar jovens oprimidos pela exclusão social para as fileiras da Al Qaeda (irmãos Kouachi) e do Estado Islâmico (Coulibaly). Estes agrupamentos extremistas alimentam-se dos ataques neocolonialistas aos países árabes e do desmonte do estado social[...] As expectativas de progresso dos filhos dos imigrantes estimuladas pelo acesso ao ensino superior sucumbiram ao subemprego, à degradação social das periferias e à violência policial [...] (No período pós-fordista), o trabalhador europeu passou a caçoar dos imigrantes (e seus descendentes) precariados [...] por serem uma ameaça às suas conquistas trabalhistas.

Por tudo isso, Slavoj Zizek ${ }^{9}$ critica a hipocrisia dos participantes da Marcha da República: "os ataques terroristas conseguiram o impossível: reconciliar a geração de 1968 com seu arqui-inimigo em algo como uma versão popular francesa do Patriot Act, com pessoas se voluntariando para serem vigiadas.". Nesse sentido, Gilberto Maringoni10 adverte sobre o perigo do auge de um nacionalismo eurocêntrico que "repulsa aos estrangeiros pobres, potencializado por um nacionalismo conservador. Estariam em perigo a cultura e o modo de vida de uma hipotética nação profunda".

\footnotetext{
7 BADIOU, Alain. “A farsa de Charlie Hebdo”, Blog da Boitempo, 2015.

8 Op.cit.

9 ZIZEK, Slavoj. “Eu sou estúpido e maldoso”, Blog da Boitempo, 2015.

10 Op.cit.
} 
Com tudo, para nós, fica inaceitável tentar justificar o massacre porque a revista francesa provocava com suas caricaturas blasfêmicas. Slavoj Zizek"11 afirma que "Não há nada de islamofóbico em condenar as chacinas de Paris". Mas, lembramos que Charlie Hebdo, com seus ataques a Maomé, estava inserida em uma disputa maior. Para Zizek ${ }^{12}$, "Charlie Hebdo ao partir de uma posição de ironia de todas as autoridades deslizou em uma sensibilidade aguçada à humilhação do outro". Luiz Nassif ${ }^{13}$ adverte que "o conceito de "humor agressivo" incentiva linchamentos, ataques a indivíduos, mesmo cidadãos comuns, desmoralização de defeitos físicos, exploração do preconceito racial, social e religioso. E nada acontece.". Ruy Braga ${ }^{14}$ repara na função do humor: “O humor pode cumprir dois papéis: a integraçãosocial via banalização das diferenças ou a segregação via estereotipação e essencialização das subjetividades.”.

O terrorismo é uma questão transnacional, por isso, sua solução exigirá uma cooperação transnacional das forças democráticas para enfrentá-lo. Hoje em dia, ninguém está protegido de ataques terroristas, de modo que urge mais diálogo entre as culturas, senão estaremos participando da criação de Frankensteins. Temos que fazer intercâmbios culturais, onde possamos aprender com nossas diferenças e nos desenvolver livremente como seres humanos. Para isso, precisamos ficar atentos ao novo nas linguagens, nas identidades e nos seus sentidos. Seguindo o escritor moçambicano Mia Couto15, precisamos abandonar as mentalidades dos guetos e aventurar além da fronteira, dos muros de nossa língua, cultura, e território.

\footnotetext{
11 ZIZEK, Slavoj. “Eu sou estúpido e maldoso”, Blog da Boitempo, 2015.

12 Op.cit.

13 NASSIF, Luiz. "Não confunda terrorismo com atentado à liberdade de imprensa". GGN, 2015.

http://jornalggn.com.br/noticia/nao-confunda-terrorismo-com-atentado-a-liberdade-de-imprensa 14 Ibid.

15 COUTO, Mia. "Murar o medo: Há quem tenha medo que o medo acabe", Conferências do Estoril, (Cascais) Portugal, 2011. https://www.youtube.com/watch?v=jACccaTogxE
} 